\title{
APPLICATION CONCEPTS OF SMALL REGENERATIVE CRYOCOOLERS IN SUPERCONDUCTING MAGNET SYSTEMS
}

\author{
M.T.G. van der Laan R.B. Tax H.H.J. ten Kate
}

University of Twente, Applied Superconductivity Centre, P.O. Box 217, 7500 AE Enschede, The Netherlands

\begin{abstract}
Superconducting magnets are in growing use outside laboratories for example MRI scanners in hospitals. Other applications under development are magnet systems for separation, levitated trains and ship propulsion. The application of cryocoolers can make these systems more practical. Interfacing these cryocoolers to the magnets can be designed in several different ways. The four basic methods will be dealt with. Test results of a realized GM cryocooler-si magnet system will be shown. It handles about a $1: 3$ scale MRI magnet of which one of the six coils has been successfully tested at temperatures between 10 and $14 \mathrm{~K}$.
\end{abstract}

\section{INTRODUCTION}

Relatively small SC magnets can be economically cooled by cryocoolers. Each application has its own user needs but most of them have in common [1]:

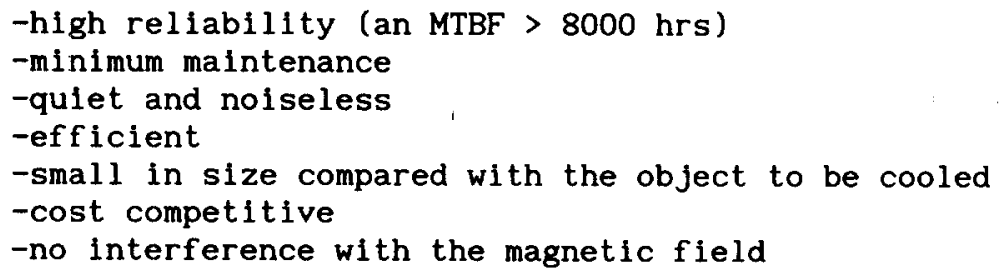

The cryocoolers to be used are most likely Stirling, Vuilleumier or Gifford-McMahon machines. The temperatures that can be reached are typically $8 \mathrm{~K}$. When a thermal load and the interface between cooler and magnet is added the temperature of the magnet will be in the range 10-14 $\mathrm{K}$ depending on the system. In any case it implies the use of Nb3Sn superconductor or in the future HTC conductors like Bi based tapes. When a JT-loop is added to the cooling system then it is possible to use the reliable and inexpensive $\mathrm{NbTi}$.

\section{INTERFACING CRYOCOOLERS AND SC MAGNETS}

Basically there exist four types of interfaces:

-He bath cooling with an added JT-loop [2]

-indirect LHe cooling using a thermosifon and a JT-loop [3]

-indirect GHe cooling using a forced flow system

-cooling by means of conduction only [4].

A JT-loop requires a more complex system although there is the advantage to use NbTi. When the cooling is involved with LHe or GHe it is the cryostat which becomes more complex. A conduction cooled system is inherently simple, reliable and deficient in maintenance. It depends on the type of magnet system which type of interface and cryocooler is preferable. We will consider five examples of SC magnets as there are MRI [4], high gradient magnetic separation [5], magnetic train levitation [6], homopolar motors for ship propulsion [7], and linear motors application in steel making processes [8]. The preferable configurations are shown in Table 1. To our opinion the combination of GM coolers and a dry MRI system for $10-14 \mathrm{~K}$ is a good solution, as presented in the next section. 


\section{A MAGNET SYSTEM INCORPORATING CRYOCOOLERS}

In our laboratory a conduction cooled magnet system has been developed which can be

Table 1 Preferable configurations for cooling interfaces

\begin{tabular}{|c|c|c|c|c|c|}
\hline \multicolumn{2}{|c|}{$\begin{array}{l}\text { Interface } \\
\text { Temperature (K) }\end{array}$} & $\begin{array}{l}\text { He bath } \\
\text { JT } \\
4.2\end{array}$ & $\begin{array}{l}\text { ind. LHe } \\
\text { JT } \\
4.2\end{array}$ & $\begin{array}{l}\text { ind. GHe } \\
10-14\end{array}$ & $\begin{array}{l}\text { conduction } \\
10-14\end{array}$ \\
\hline Magnet & $\begin{array}{l}\text { MRI } \\
\text { HGMS } \\
\text { MAGLEV } \\
\text { Ship } \\
\text { LIM }\end{array}$ & $\begin{array}{l}\text { GM } \\
\text { GM } \\
\text { GM } \\
\text { GM } \\
\text { V }\end{array}$ & $\begin{array}{l}\mathrm{S} \\
\mathrm{S} \\
\mathrm{S} \\
\mathrm{S} \\
\mathrm{S}\end{array}$ & $\begin{array}{l}\mathrm{S} \\
\mathrm{S} \\
\mathrm{S} \\
\mathrm{S} \\
\mathrm{S}\end{array}$ & $\begin{array}{l}\text { GM } \\
\text { GM } \\
\text { GM } \\
\text { GM } \\
\text { V }\end{array}$ \\
\hline
\end{tabular}

S: Stirling V: Vuilleumier GM: Gifford-McMahon

seen as a 1:3 scale MRI magnet. It is cooled by two GM cryocoolers [9], [10]. The general layout and the winding cross section is shown in Figure 1 and Figure 2. The conductor is a Nb3Sn wire with a diameter of $0.6 \mathrm{~mm}$ and is isolated with a glass braid. The coil is wound, then reacted followed by a vacuum impregnating process. The heat loads on the system are shown in Table 2 while the main magnet parameters are given in Table 3.

Table 2 Heat loads on the system in $\mathrm{W}$

\begin{tabular}{|l|c|l|}
\hline & Shield 50 K & Magnet 12 K \\
\hline Radiation & 20 & 0.008 \\
Conduction & 2.2 & 0.012 \\
Power leads & 9.2 & 0.78 \\
\hline Summation & 31.4 & 0.8 \\
\hline
\end{tabular}

Table 3 Main magnet parameters

\begin{tabular}{|ll|ll|}
\hline Magnet bore & $400 \mathrm{~mm}$ & Central field & $1.0 \mathrm{~T}$ \\
Warm bore & $330 \mathrm{~mm}$ & Max. field & $1.9 \mathrm{~T}$ \\
Magnet length & $600 \mathrm{~mm}$ & Shield mass & $45 \mathrm{~kg}$ \\
Operating current & $100 \mathrm{~A}$ & $12 \mathrm{~K}$ cold mass & $65 \mathrm{~kg}$ \\
\hline
\end{tabular}

\section{TEST RESULTS}

The first tests were performed with one of the six colls e.g. the third coil from the cold head side. The cold mass of this coll including all thermal, electrical and mechanical connections is $13 \mathrm{~kg}$. The cooldown curves are shown in Figure 3 . With two cold heads and two compressors of the types RGD 580 and RW 5 from Leybold respectively connected to a shield of $45 \mathrm{~kg}$ the cooldown time was roughly about $1 \mathrm{hr} / \mathrm{kg}$. A similar performance was observed for other previously installed cold masses varying unto $45 \mathrm{~kg}$.

The temperature gradients over the magnet when it was energized are shown in Figure 4. The origin of this gradient lies in the fact that the lead terminals are opposing each other. At $140 \mathrm{~A}$ the coil quenched. There were no training effects noticed to reach this current. The maximum temperature gradient over the magnet during a quench is shown in Figure 5. The coil is ramped to $140 \mathrm{~A}$ and the temperature starts slowly to rise while the quench follows after some 6 minutes.

These results are obtained with cold heads where the second stage regenerator 
material is the usual $\mathrm{Pb}$. The regenerator matrix was then replaced by the new material Er3Ni and the cooling down was repeated showing practically the same curves as in the case of the $\mathrm{Pb}$ matrix. The end temperatures of the cold heads and the magnet are indeed lower and are summarized in Table 4.

Table 4 End temperatures for two regenerator materials in $\mathrm{K}$

\begin{tabular}{|c|c|c|c|}
\hline & & Cold head & Coil \\
\hline Regenerator: & $\begin{array}{l}\mathrm{Pb} \\
\mathrm{Er} 3 \mathrm{Ni}\end{array}$ & $\begin{array}{ll}9.2 \mathrm{~K} \\
7.3 \mathrm{~K}\end{array}$ & $\begin{array}{l}10.3 \mathrm{~K} \\
8.9 \mathrm{~K}\end{array}$ \\
\hline
\end{tabular}

\section{CONCLUSIONS}

It was shown that it is possible to create a conduction cooled Nb3Sn magnet system which can be cooled down within a reasonable time and reaching its maximum current without training.

The exchange of the $\mathrm{Pb}$ regenerator matrix by Er3Ni showed no difference in the cooldown behaviour of the system. The end temperatures of the magnet are indeed lowered with $1.4 \mathrm{~K}$.

\section{ACKNOWLEDGEMENTS}

This research in the program of the Foundation for Fundamental Research on Matter FOM has been supported in part by the Netherlands Technology Foundation STW.

\section{REFERENCES}

1 Schwall, R.E. and Harris, W.S., Packaging and cooling low temperature electronics Advances in cryogenic engineering (1992) 37 587-596

2 Longsworth,R.C., Interfacing small closed cycle refrigerators to liquid helium cryostats Cryogenics (1984) 24 175-178

3 Wada, T. and Sato, T., Basic experiment on the indirect cooling for superconducting magnets Advances in cryogenic engineering (1990) $35849-856$

4 GE, Patent 0350267 Superconductive magnetic resonance magnet, date of filing 04.07 .89

5 Luguang, $Y$ et al, Development of the superconducting magnet system for industrial high gradient magnetic separator IEEE Transactions on magnetics (1991) 27 2276-2279

6 Tsuchischima,H. and Herai, T., Superconducting magnet and on board refrigeration system on japanese maglev vehicle IEEE Transactions on magnetics

(1991) $272272-2275$

7 Stevens, H., Superconducting machinery for ship propulsion Advances in cryogenic engineering 35 539-545

8 Tsukamoto, 0 . et al, Development of superconducting linear induction motor for steel making process IEEE Transactions on magnetics 27 2248-2251

9 van der Laan, M.T.G., Tax, R.B., ten Kate, H.H.J., van de Klundert, L.J.M., A $12 \mathrm{~K}$ superconducting magnet system, cooled by thermal conduction by means of cryocoolers, Paper presented at CEC 91

10 van der Laan, M.T.G., Tax, R.B., ten Kate, H.H.J., van de Klundert, L.J.M., Test results of a Nb3Sn magnet cooled by cryocoolers, Paper presented at ASC 92 

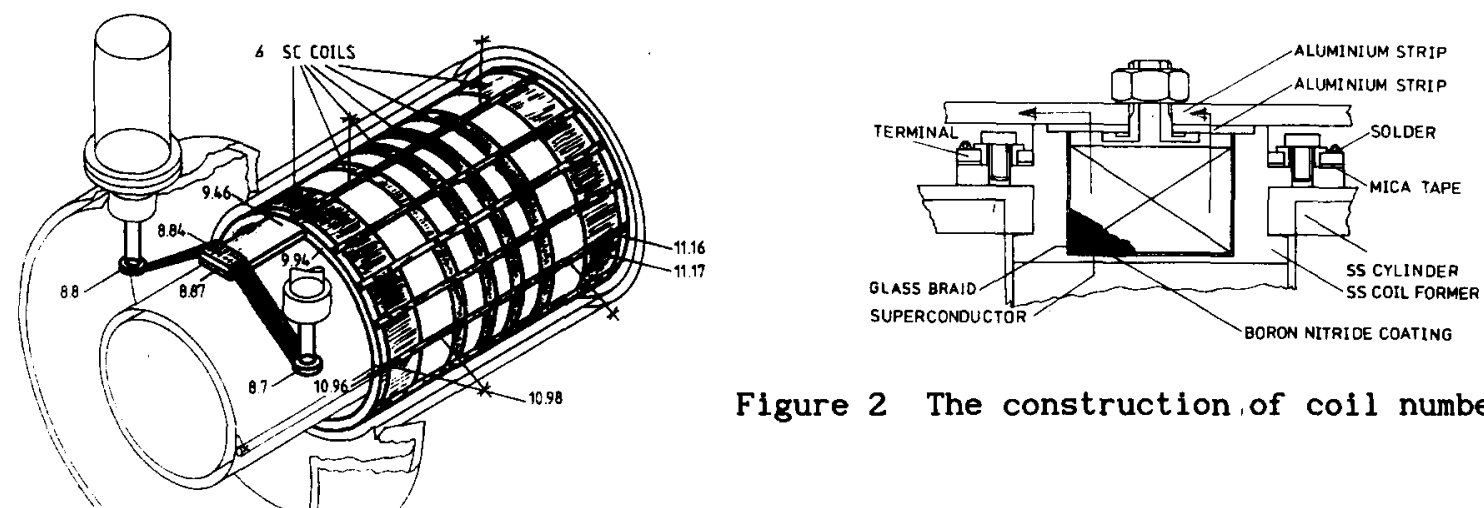

Figure 2 The construction of coil number 3

$T(K)$

Figure 1 General layout of the magnet system

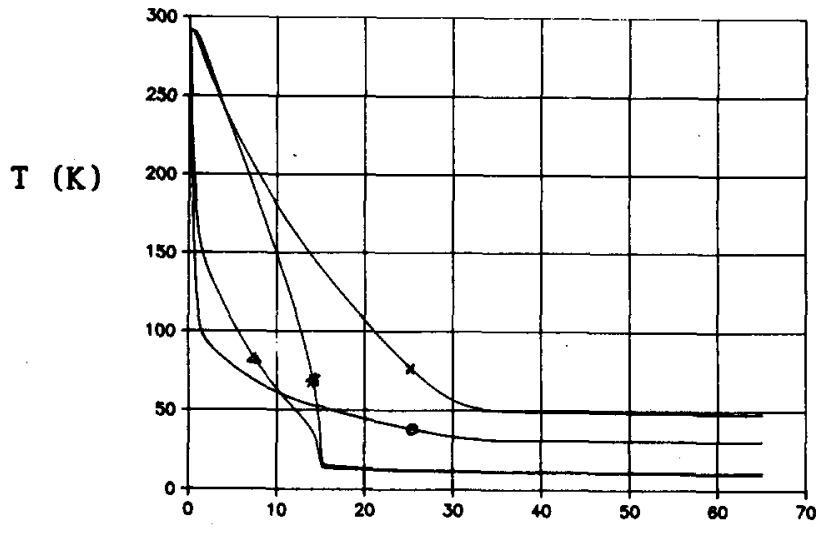

$x$ shield

* magnet

$\Delta$ second stage

- first stage

Figure 3 The cooling down of coll number 3

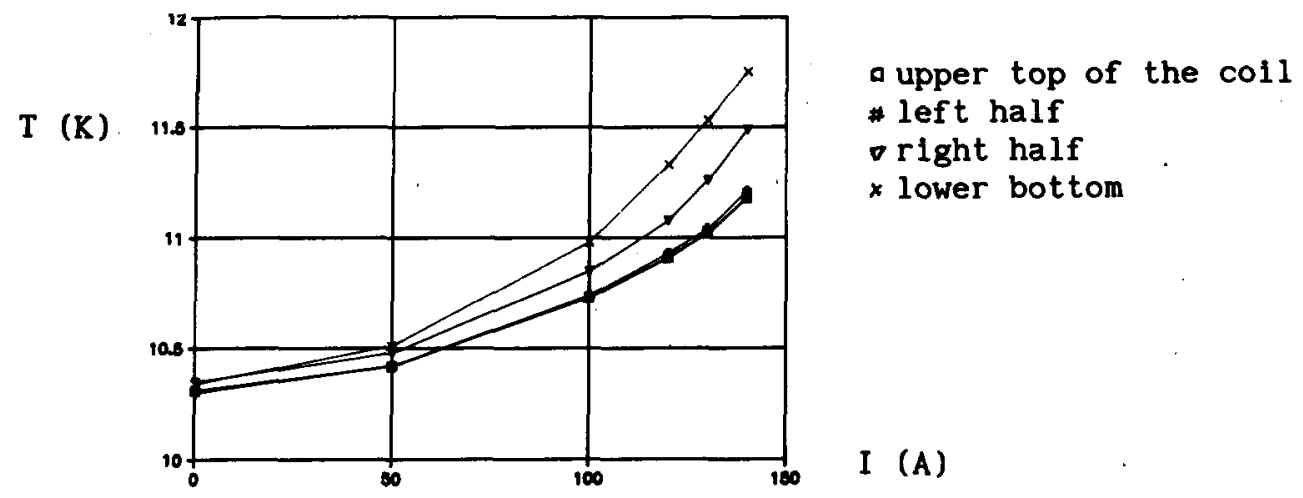

Figure 4 The maximum temperature gradients over the coil windings as a function of the energizing current

$T(K)$

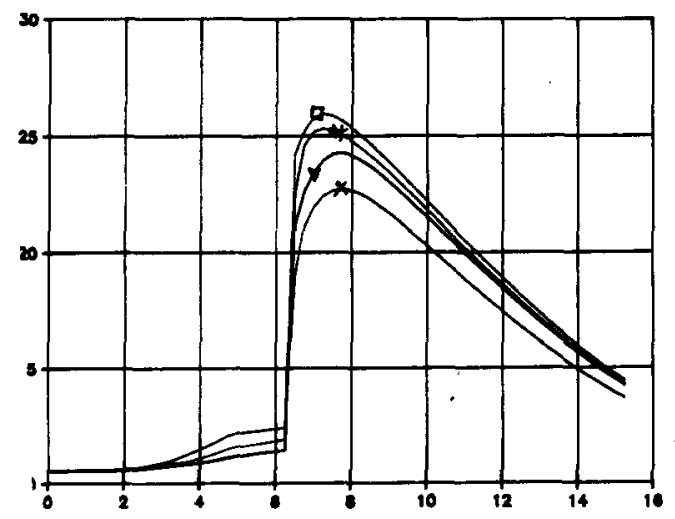

- upper top of the coll

* left half

- right half

$\times$ lower bottom

$\operatorname{TIME}(\mathrm{min})$

Figure 5 The maximum temperature gradient over the coil winding after a quench at $140 \mathrm{~A}$ 